\title{
EDITORIAL
}

\section{Intergenerational Global Heath}

\author{
David M. Shaw • Leigh E. Rich
}

Received: 5 January 2015 / Accepted: 16 January 2015 /Published online: 25 February 2015

(C) Journal of Bioethical Inquiry Pty Ltd. 2015

This special issue of the Journal of Bioethical Inquiry focuses on global health and associated bioethical concerns. As a concept, global health broadens the focus from national public health situations to the international sphere and concerns itself with the health of all humans, but particularly those in developing countries who suffer from severe health inequalities. However, there is one sense in which global health is lacking: Its primary focus is on those currently alive and, in some cases, their offspring. But what about future generations, who may suffer from even more pronounced inequalities? In this editorial, we consider the bioethical implications of failing to adopt an intergenerational concept of global health.

One of the major strengths of global health is its emphasis on disenfranchised populations who do not enjoy the advantages of the medical systems of developed countries. By drawing attention to the issues that affect billions of disadvantaged people around the world, global health campaigns attempt to reduce the moral distance that makes many in developed countries neglect the needs of those most in need in other

D. M. Shaw $(\bowtie)$

Institute for Biomedical Ethics, University of Basel,

Bernoullistrasse 28, CH-4056 Basel, Switzerland

e-mail: david.shaw@unibas.ch

\section{E. Rich}

Department of Health Sciences (Public Health), Armstrong State University, 11935 Abercorn Street, University Hall

154F, Savannah, GA 31419, USA

e-mail: leigh.rich@armstrong.edu countries. It is unsurprising that governments (and people donating to charity) have tended to focus on looking after their own citizens first, but increasing public awareness of the effects of disease, famine, drought, and natural disasters - and how such events may have ramifications on distant, seemingly unconnected populations - has in turn led to greater investment in improving global health, with beneficial consequences for those most immediately affected.

However, it can be argued that global health does not go far enough. First, although some work is currently being done in this area, we still tend to paint the "global world" with a broad and unwieldy brush. Health, economic, social, and political disparities occur in the developing world but also throughout societies that seemingly should have health-promoting and healthprotecting infrastructures in place as well as access to health care and socioeconomic opportunities for their citizens. As Hans Rosling demonstrates in a 2006 TED Talk, there's "a tremendous variation" within global health regions and within countries (Rosling 2006, 10:17), but we continue to view the world from a binary perspective (rich-poor, developed-developing) and "look at the average data of the countries" (Rosling 2006, 13:40).

Now that's dangerous, to use average data, because there is such a lot of difference within countries. ... [For example, we can split countries into quintiles and compare, say, the poorest 20 percent of Niger with the richest 20 percent of South Africa], and yet we tend to discuss on what 
solutions there should be in Africa. Everything in this world exists in Africa. And you can't discuss universal access to HIV [medicine] for that quintile up here with the same strategy as down here. The improvement of the world must be highly contextualized, and it's not relevant to have it on [a] regional level. We must be much more detailed (Rosling 2006, 13:47-14:53, emphasis original).

In an "emperor with no clothes" moment, Rosling then asks what many may not be able or willing to see: "Now, why doesn't this take place? Why are we not using the data we have? We have data in the United Nations, in the national statistical agencies, and in universities and other nongovernmental organizations" (Rosling 2006, 15:04-15:16). It is because, he says, "the data is hidden down in the databases," the data is hidden in plain sight (Rosling 2006, 15:17). And despite the public funding that has gone into the production and assessment of much of this data and the existence of the Internet and other digital technologies that increasingly facilitate its sharing, analysis, and dissemination of results, "we are still not [using] it effectively" (Rosling 2006, 15:21).

Second, while it is certainly extremely important to address global health inequalities for those currently alive, the importance of the billions of people in need today pales into relative insignificance when compared with the hundreds of billions of people who will live on this planet in the future. Improving the health of those alive now will undoubtedly benefit the next generation and probably the one after that, but global health doesn't even go as far into the future as Darwinian natural selection ${ }^{1}$ - it seems to draw a line at pregnant women and their unborn children. This moral myopia represents another form of moral distance; this time temporal, rather than geographical. To be truly global, global health also must consider future generations and their health needs.

It is quite surprising that global health has not risen to the challenge of addressing future health inequalities, particularly given the global health implications of climate change that could prove catastrophic within the foreseeable future for (and may already be affecting)

\footnotetext{
${ }^{1}$ The "meaning of life" or "success" in bare-minimum evolutionary terms is the ability to produce the next generation capable of producing its own next generation (i.e., the ability to produce fertile offspring).
}

many millions of people. Much climate change discourse focuses on the effects of global warming not only for current but also for future generations, with one key consideration being how we should take future people into account in our fight against climate change. Should we only focus on those alive now and in the near future? Should we include future generations in our calculations and predictions and give them equal weight to those currently alive? ${ }^{2}$ Or should we apply future discounting, which would attribute less value to the lives of future people the further into the future they are?

These difficult questions become even more complex in the context of global health. The simple fact that successful global health campaigns can transform the lives of millions of people raises serious issues for future generations. If hundreds of thousands of people are saved from famine and disaster, that in turn means that hundreds of thousands of babies will be born who otherwise would not have been. In addition to the direct impact this will have on climate change, will the health care of these future generations be of the same or better standard available to their parents? ${ }^{3}$ And on a more basic level, if true global health for those currently alive is ever achieved, the life expectancy in most countries in the world will increase substantially, both for current and for future generations. Does our planet have enough resources to withstand the ultimate success of current global health efforts - particularly if we don't shape current global health efforts in terms of long-term sustainability and reshape current individual and societal expectations of what it means to prosper? Of course, we are not arguing here that hands should be "washed" and eyes turned away from the suffering of existing individuals, families, and communities experiencing sociopolitical and economic oppression, endemic and epidemic

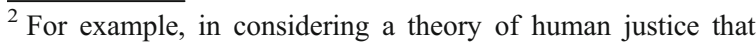
"evaluate[s] human actions that might affect future generations," Jan Deckers has argued that since "the negative GHIs [a unit of measurement of global health impact] of our current generation cause unfair harm to future generations ... each human being must be allocated a fair threshold of negative GHIs that should not be exceeded" (Deckers 2011, 165).

${ }^{3}$ Of course, the issue of access will always continue to raise its hoary head, and we must add here "and for whom?" (for which members of those future generations?). For while our understandings of health and disease seem to progress exponentially as time beats on, access to such technologies and other health-related resources don't always follow suit.
} 
disease, and/or natural disasters and all for the sake of future potential individuals, families, and communities. But we cannot remain so shortsighted, either. In a world where industry looks ahead only as far as the next quarter-with a benchmark for success defined solely as continued growth-and where public health is beholden to legislators' and grantmakers' short-range election and funding cycles, no one is taking the long view (especially since many of those in leadership positions won't even acknowledge the implications of issues like climate change, overuse of resources, and microbial resistance). Even global health organizations mark time in decades rather than centuries (e.g., Healthy People 2020, Millennium Development Goals). True, this is in part to make sure we set attainable objectives and to remind ourselves to regularly revisit and reevaluate the status quo and our progress. These are good reasons for focusing geographically and temporally and should not be unfairly criticized (like the ostrich who was once thought to bury its head in the sand but actually is just "dig[ging] holes in the dirt to use as nests for [its] eggs" [Lovgren n.d., 94]). That said, this should not come at the expense of sustainable farsightedness.

Essentially, successful global health efforts can create serious global health problems in the future. People whose lives are saved by global health efforts may live for decades more, consuming resources all the while. They also will likely have children who would otherwise not have existed and who will in turn consume resources (and have sizeable carbon footprints, particularly if current standards and practices of "comfortable" living continue in lieu of environmentally and healthfriendly changes in human behavior, systems, and infrastructures). Each life saved by global health efforts is a wonderful achievement and there is an obligation to do so, but the consequences of successful global health efforts for future generations (both in the country in question and in others) must begin to be taken into account. This means focusing on comprehensive, longrange, sustainable approaches that foster societies and built environments invested in the "global community" - the one that exists now and all of those that (we hope) will exist in the future. This likely will involve redressing socioeconomic gaps in real ways, addressing population and family size, and redefining "affluence" and "success." Of course, it is not just global health but also all health care and medicine, especially in developed countries, that increase life expectancy and, concomitantly, lead to a higher consumption of resources. One of the reasons citizens in Western countries consume so many resources is because of our longer life expectancies, but it is also due to standards of living rooted in notions of progress and the "good life" that haven't changed much since the Industrial Revolution and in political and economic approaches that resist regulation and other limitations. In global health, we seek to raise everyone to a comparable level of life expectancy, but will the world have enough resources to cope with this massively increased demand (particularly without widespread industrial, political, and lifestyle changes)?

It is widely recognized that the world's increasing population is an important factor in global warming and other pressing health issues, yet the role played by global health in maintaining and increasing population has been somewhat neglected. Thus, it is entirely possible that successful global health efforts, without a concerted refinement of the scope and goals of global health, could actually ultimately reduce the quality of life of future generations by contributing to unsustainable population growth. The 1987 Bruntland Report stated that sustainable development "meets the needs of the present without compromising the ability of future generations to meet their own needs" (World Commission on Environment and Development 1987, 43).

It is possible that achieving good global health for all will only be sustainable if restrictions are placed on individual and corporate rights - to take one example, limiting family size. This, undoubtedly, (re)opens a thorny bioethical issue that raises the specter of eugenics and gender selection bias/infanticide, among others. We need not look back very far for lessons in the misapplication of discredited science and bad policy in the name of "public well-being": Compulsory sterilization laws were passed and practiced in multiple countries and continued well into the $20^{\text {th }}$ century (for an in-depth scientific, legal, and social overview of the rise of these laws, see Lombardo 2008). Even China, for various reasons and with yet-unknown ramifications, recently relaxed its one-child policy (Hunt 2015; The Economist 2015; Kuhn 2015).

If we are right that global health is too focused on current and near-future needs, without enough (or any) consideration of the needs of future generations, what can be done to address this? Key future questions for global health include: 
- What are the consequences for future generations if this project succeeds?

- Are enough resources being safeguarded for future generations?

- What new health threats will future generations face?

- Might it be necessary to curtail aspects of global health efforts in cases where maximizing current global health would threaten the health of future generations?

Another important consideration not normally regarded as being a concern of global health is the possibility of global catastrophe at some point in the future. Even excluding catastrophic climate change, there is a small chance that life on earth could be eradicated by a meteor or extreme solar activity or nuclear war or deadly zoonosis. Intergenerational global health also must concern itself with these issues; keeping everyone in a house healthy is a pointless endeavor if no measures are taken to stop a plane crashing into it. Ultimately, a key concern of global health might become how best to keep people healthy in other locations than this planet - particularly given some of the concerns mentioned above and the risk of global overpopulation.

Just as moral distance can be both geographical and temporal, so global health must also consider the lives of those who will live on this planet (and beyond) in the future. As Rosling emphasized in his TED Talk, "health cannot be bought at the supermarket. You have to invest in health. You have to get kids into schooling. You have to train health staff. You have to educate the population" (Rosling 2006, 13:14). And this training and education must include a far-reaching perspective that teaches us to consider not just ourselves and our families but also our neighbors across the world and into the future. Only by becoming intergenerational can global health ensure that all present and future health inequalities can be addressed.

\section{References}

Deckers, J. 2011. Negative "GHIs," the right to health protection, and future generations. Journal of Bioethical Inquiry 8(2): $165-176$.

Hunt, K. 2015. Two kids? Thanks but no say some Chinese. CNN International, January 13. http://edition.cnn.com/2015/01/13/ china/china-one-child-policy/.

Kuhn, A. 2015. One county provides preview of China's looming aging crisis. NPR, January 14. http://www.npr.org/blogs/ parallels/2015/01/14/377190697/one-county-providespreview-of-chinas-looming-aging-crisis.

Lombardo, P. 2008. Three generations, no imbeciles: Eugenics, the Supreme Court, and Buck v. Bell. Baltimore: The Johns Hopkins University Press.

Lovgren, S. No date. Animal myths busted. National Geographic Kids. http://kids.nationalgeographic.com/explore/nature/ animal-myths-busted/. Accessed January 14, 2015.

Rosling, H. 2006. The best stats you've ever seen. TED2006, February. http://www.ted.com/talks/hans_rosling_shows the_best_stats_you_ve_ever_seen\#t-936521. Accessed January $14,2015$.

The Economist. 2015. Enforcing with a smile: Enforcers of China's one-child policy are trying a new, gentler approach. The Economist, January 10. http://www.economist.com/ news/china/21638131-enforcers-chinas-one-child-policyare-trying-new-gentler-approach-enforcing-smile.

World Commission on Environment and Development. 1987. Our common future. Oxford: Oxford University Press. 